\title{
Pure platinum nanostructures grown by electron beam induced deposition
}

\author{
Chris Elbadawi, Milos Toth,Charlene J. Lobo* \\ School of Physics and Advanced Materials, University of Technology, Sydney, P.O. Box 123, \\ Broadway, New South Wales 2007, Australia \\ E-mail: Charlene.Lobo@uts.edu.au
}

\begin{abstract}
Platinum has numerous applications in catalysis, nanoelectronics and sensing devices. Here we report a method for localized, mask-free deposition of high purity platinum that employs a combination of room temperature, direct-write electron beam induced deposition (EBID) using the precursor $\mathrm{Pt}\left(\mathrm{PF}_{3}\right)_{4}$, and low temperature $\left(\leq 400^{\circ} \mathrm{C}\right)$ post-growth annealing in $\mathrm{H}_{2} \mathrm{O}$. The annealing treatment removes phosphorous contaminants through a thermally activated pathway involving dissociation of $\mathrm{H}_{2} \mathrm{O}$ and the subsequent formation of volatile phosphorus oxides and hydrides that desorb during annealing. The resulting Pt is indistinguishable from pure Pt films by wavelength dispersive x-ray spectroscopy (WDS).
\end{abstract}

\section{Introduction}

Vapour-phase fabrication of nanoscale metals most commonly employs organometallic precursors. Gas-mediated, focused electron beam induced deposition (EBID) ${ }^{1}$ is one such fabrication technique that offers several advantages over commonly employed technologies like chemical

\footnotetext{
*To whom correspondence should be addressed
} 
vapor deposition and atomic layer epitaxy. Most significantly, EBID permits room temperature localized deposition with high $(<10 \mathrm{~nm})$ resolution without the use of lithographic masks and resists. ${ }^{2,3}$ Structures fabricated using EBID include nanodot (Figure 1(a)) and wire arrays, ${ }^{2-4}$ magnetic nanowires ${ }^{5}$ and tips for magnetic force microscopy, ${ }^{6}$ contacts to nanowires and carbon nanotubes, ${ }^{7}$ plasmonic nanostructures ${ }^{8}$ and metallic seeds used to catalyze the growth of individual nanowires. ${ }^{9}$ The main limitation of EBID is that the deposited materials are typically highly impure, consisting of metal or oxide grains with a diameter of $\sim 1-5 \mathrm{~nm}$ embedded in an amorphous matrix rich in precursor ligand constituents. ${ }^{1,6,10-18}$ The precursors are often organometallics and the matrix generally contains $\gtrsim 50$ at.\% carbon, yielding deposits that behave as granular materials with percolative transport properties. ${ }^{11-14,19}$

Previously, relatively high purity EBID-grown materials have been realized in a limited number of cases, where (i) low-carbon-content precursors are available, ${ }^{20-26}$ (ii) substrate heating or precursor gas mixtures are used to improve purity, ${ }^{26-31}$ (iii) ultra-high-vacuum techniques are used to produce ultra-clean, reactive substrate surfaces, ${ }^{32,33}$ or (iv) annealing, ozone, electron or plasma processing is used to modify as-grown deposits. ${ }^{1,8,10,34,35}$ However, EBID purity is inadequate for the fabrication of most devices and functional materials.

Fabrication of Pt has attracted more attention than any other EBID-grown material. However, to date, there exists no technique for EBID of highly pure (>90 at.\%) Pt. Best results have been achieved using the precursor $\mathrm{Pt}\left(\mathrm{PF}_{3}\right)_{4},{ }^{21-26,34}$ which yields deposits in which phosphorus and fluorine have been found to be the major contaminants (oxygen is missing from most prior analyses). We note that highly pure Pt deposits have been demonstrated using a combination of an EBID-grown seed layer and atomic layer deposition (ALD), ${ }^{36}$ or by $\mathrm{XeF}_{2}$-mediated, fluorineinduced decomposition of $\mathrm{Pt}\left(\mathrm{PF}_{3}\right)_{4}$ adsorbates. ${ }^{37}$ However, both of these techniques exhibit lateral growth rates that are approximately equal to the corresponding vertical growth rates. They can therefore not be used for the growth of high resolution, high aspect ratio deposits, and limit the attainable geometries of self-supporting three-dimensional nanostructures.

Here, we demonstrate the fabrication of highly pure platinum achieved by EBID of $\mathrm{Pt}\left(\mathrm{PF}_{3}\right)_{4}$ in 
combination with post-growth removal of phosphorous contaminants by low temperature annealing in $\mathrm{H}_{2} \mathrm{O}$. The deposits contain $>94$ at. \%Pt, and are indistinguishable from reference Pt standards by wavelength dispersive x-ray spectroscopy (WDS). The required annealing temperature is sufficiently low $\left(\leq 400^{\circ} \mathrm{C}\right)$ to prevent both the decomposition of the Pt deposits and chemical etching of the substrate (which are observed at higher annealing temperatures). The purification method is both more effective and more widely applicable than prior methods involving substrate heating during EBID, and post-deposition annealing in vacuum, $\mathrm{O}_{2}$ and $\mathrm{NH}_{3}$ environments.

\section{Methods and materials}

The EBID precursor Tetrakis(trifluorophosphine) platinum $\mathrm{Pt}\left(\mathrm{PF}_{3}\right)_{4}$ (Strem chemicals) is a high vapour pressure liquid at room temperature. It was loaded into a peltier-cooled stainless steel crucible under dry $\mathrm{N}_{2}$, which was subsequently removed using multiple freeze-pump-thaw cycles. EBID was performed using an environmental scanning electron microscope (SEM) equipped with a thermionic tungsten hairpin electron source. An in-situ environmental sub-chamber enabled control over the substrate temperature during EBID, as described in Ref. ${ }^{28,38}$ The sub-chamber was isolated from a differentially pumped electron column using a $200 \mu \mathrm{m}$ pressure limiting aperture. After pump-down to $\sim 10^{-4} \mathrm{~Pa}$, the pressure in the sub-chamber was maintained at $13 \mathrm{~Pa}$ using a pressure-feedback gas delivery system. A $10 \mathrm{keV}, 10 \mathrm{nA}$, top-hat electron beam ${ }^{17,18}$ was defocused to a diameter of $\sim 5 \mu \mathrm{m}$, yielding an electron beam flux of $\sim 3 \times 10^{17} \mathrm{e}^{-} / \mathrm{cm}^{2} / \mathrm{s}$. Deposits such as the one shown in Figure 1(b) were grown using a stationary, normal incidence beam on Si (111) substrates (with a native oxide), with a growth time of 30 minutes.

After deposition, samples were transferred in air to an ex-situ vacuum chamber (base pres-

sure $\sim 10^{-4} \mathrm{~Pa}$ ) equipped with a heating stage and a gas flow delivery system. Annealing was performed in vacuum, and in $\mathrm{H}_{2} \mathrm{O}, \mathrm{O}_{2}$ and $\mathrm{NH}_{3}$ environments (pressure $\sim 130 \mathrm{~Pa}$ ). Compositional analysis was performed using a high vacuum SEM equipped with WDS. WDS was used instead of the more common energy dispersive x-ray spectroscopy (EDS) because WDS enables resolution of 
the $\mathrm{P} \mathrm{K}_{\alpha}$ and $\mathrm{Pt} \mathrm{M}_{\alpha}$ X-ray peaks which overlap in EDS spectra, as shown in Figure 1(c). WDS was performed using a beam energy of $10 \mathrm{keV}$ to ensure that the electron interaction volume (simulated using standard Monte Carlo simulators of electron-solid interactions ${ }^{39}$ was contained within the deposit (such as the one shown in Figure 1(b)). Standards of known elemental composition were used to quantify WDS data, with a reproducibility of $\pm 2 \%$. Each deposit was analyzed once only, either immediately after growth, or after a single post-growth anneal.

\section{Results and discussion}

\section{As-grown deposits}

Deposits grown at room temperature have a typical atomic composition of $47 \pm 5 \% \mathrm{Pt}, 30 \pm 5 \% \mathrm{P}$ and $15 \pm 10 \% \mathrm{O}$. The composition variation is greater than the WDS analysis error of $\pm 2 \%$ because of variations between individual deposits. The spread is caused by variations in electron beam current typical of thermionic tungsten hairpin electron sources (the deposit composition is known to vary with the beam current density used for $\left.\mathrm{Pt}\left(\mathrm{PF}_{3}\right)_{4} \mathrm{EBID}\right),{ }^{22}$ and due to uncontrolled partial decomposition of $\mathrm{Pt}\left(\mathrm{PF}_{3}\right)_{4}$ by residual gas molecules present in the vacuum chamber. The measured F content decreased with air exposure time, and was at or below the WDS detection limit in samples that had been exposed to air overnight prior to WDS analysis.

The trace amounts of fluorine and the presence of oxygen in the as-grown deposits indicate efficient dissociation and desorption of $\mathrm{PF}_{3}$ and fluorine during EBID, accompanied by oxidation

of phosphorus by residual contaminants (mainly $\mathrm{H}_{2} \mathrm{O}$ ) present in the vacuum chamber. These results correspond well with those of prior ultra-high vacuum surface science studies which show that the deposition process involves these reaction pathways: ${ }^{25,26}$

$\mathrm{Pt}\left(\mathrm{PF}_{3}\right)_{4} \stackrel{-\mathrm{PF}_{3}}{\underset{\mathrm{e}^{-}}{\longrightarrow}} \mathrm{Pt}\left(\mathrm{PF}_{3}\right)_{3}$

$\mathrm{Pt}\left(\mathrm{PF}_{3}\right)_{3} \underset{\mathrm{e}-\Delta}{\stackrel{-\mathrm{F}^{-}}{\longrightarrow}} \mathrm{Pt}_{\mathrm{x}} \mathrm{P}_{\mathrm{y}}$

$\mathrm{Pt}_{\mathrm{x}} \mathrm{P}_{\mathrm{y}} \underset{\mathrm{e}-\Delta}{\stackrel{+\mathrm{H}_{2} \mathrm{O}}{\longrightarrow}} \mathrm{Pt}_{\mathrm{x}} \mathrm{P}_{\mathrm{y}} \mathrm{O}_{\mathrm{z}}$

The last two pathways occur concurrently under prolonged e-beam irradiation and/or substrate 
heating during deposition. Substrate heating during deposition can significantly improve the com-

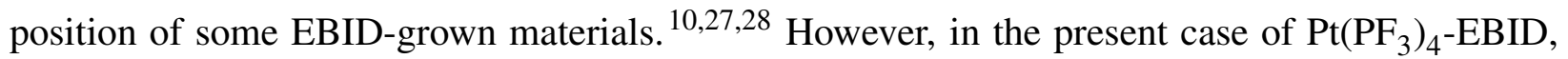
the deposit composition was observed to improve only at temperatures $\gtrsim 100^{\circ} \mathrm{C}$, reaching a Pt content of $\sim 72$ at. $\%$ at $\sim 120^{\circ} \mathrm{C}$. This extent of purification is inadequate, and the approach is impractical because $\mathrm{Pt}\left(\mathrm{PF}_{3}\right)_{4}$ has a thermal decomposition temperature of $\sim 130^{\circ} \mathrm{C}$. ${ }^{40}$ Thermal decomposition of the adsorbates causes delocalized (chemical vapor) deposition, thereby compromising the localized, direct-write capability of EBID.

\section{Post-growth annealing}

Figure 2 shows the composition of deposits annealed in vacuum $\left(\mathrm{P} \sim 10^{-4} \mathrm{~Pa}\right)$ for one hour at temperatures of 400,600 and $750^{\circ} \mathrm{C}$. Temperatures $\gtrsim 600^{\circ} \mathrm{C}$ caused significant structural decomposition of the deposits, illustrated by the image shown in Figure 2. Annealing in vacuum at temperatures $\leq 600^{\circ} \mathrm{C}$ caused an insignificant decrease in the concentration of phosphorous impurities in the deposits. Similarly, annealing in $\mathrm{O}_{2}$ and $\mathrm{NH}_{3}$ environments had no significant effect on composition at temperatures lower than the deposit decomposition temperature.

Conversely, low temperature annealing in $\mathrm{H}_{2} \mathrm{O}$ vapor can increase the $\mathrm{Pt}$ content to a degree that is indistinguishable from reference, high purity Pt films by WDS analysis. Figure 3 shows the deposit composition as a function of $\mathrm{H}_{2} \mathrm{O}$ annealing time at 250 and $400{ }^{\circ} \mathrm{C}$. At $400^{\circ} \mathrm{C}$, annealing times of 20, 40 and 300 minutes yield Pt concentrations of $\sim 75,92$, and 94 at.\%, and P concentrations of $\sim 17,2$ and 2 at.\%, respectively (where 2 at.\% is the P detection limit). The Pt concentration of $\sim 94$ at.\% is indistinguishable from that of a high purity, reference Pt film. The remaining $\sim 5$ at.\% (Figure 3(b)) is likely due to an oxide layer and oxygen-containing hydrocarbon contaminants that build up on the deposit surface ${ }^{41}$ during WDS analysis.

Post-growth annealing at $400^{\circ} \mathrm{C}$ did not cause structural decomposition of the deposits (see, for example, the image in Figure 1(b) which shows a deposit that had been annealed in $\mathrm{H}_{2} \mathrm{O}$ for $60 \mathrm{~min})$. We note, however, that some degree of shrinkage is expected as a result of purification. ${ }^{34,35}$ 
Annealing in $\mathrm{H}_{2} \mathrm{O}$ at $250^{\circ} \mathrm{C}$ yields the same trend as at $400^{\circ} \mathrm{C}$, but significantly longer times (approaching 24 hours) are needed to achieve equivalent Pt content (Figure 3). At $600^{\circ} \mathrm{C}$, annealing times of $<40 \mathrm{~min}$ are needed to produce deposits which are indistinguishable from reference Pt films. However, the high temperature annealing treatment causes thermal decomposition of the deposits (as in high vacuum, see Figure 2), and etching of the substrates in the vicinity of annealed deposits (shown in Figure 4). Etching at high temperatures is ascribed to phosphoric acid $\left(\mathrm{H}_{3} \mathrm{PO}_{4}\right)$ formed in a reaction with residual $\mathrm{H}_{2} \mathrm{O}$ molecules present in the vacuum chamber, and is consistent with the reported ${ }^{42}$ dependency of the etch rates of silicon and silicon dioxide on temperature.

\section{Purification mechanism and generality of the purification technique}

Our annealing results indicate that removal of phosphorous by the $\mathrm{H}_{2} \mathrm{O}$ annealing treatment is likely caused by: (i) thermal decomposition of $\mathrm{H}_{2} \mathrm{O}$ at the sample surface into reactive species such as $\mathrm{O}, \mathrm{H}$ and $\mathrm{OH}$ radicals, and (ii) reaction of $\mathrm{P}$ with these radicals to form volatile species that desorb from the solid during annealing. The volatile reaction products likely include $\mathrm{PO}_{2}, \mathrm{PH}_{3}$ and other phosphorus hydrides and oxides.

The observed decay in F content with room temperature air exposure time suggests that most of the fluorine is present in the form of residual fragments produced by partial decomposition of $\mathrm{Pt}\left(\mathrm{PF}_{3}\right)_{4}$. We note that the fluorine affects WDS analysis, and is responsible for variations in the measured $\mathrm{O}$ content of as-grown deposits such as that seen in Figure 3(b). Specifically, the shorter the air exposure time between EBID growth and WDS analysis, the greater the measured F content and the lower the measured $\mathrm{O}$ and $\mathrm{P}$ content.

The WDS quantification method assumes a uniform distribution of the elemental constituents throughout the electron interaction volume. However, the detected $\mathrm{F}$ (as well as $\mathrm{O}$ and $\mathrm{C}$ impurities that build up during WDS) are most likely concentrated at the deposit surface, and the content of these impurities is therefore overestimated by WDS analysis. Despite these limitations, our $\mathrm{H}_{2} \mathrm{O}$ annealing results show that the resulting $\mathrm{Pt}$ deposits are indistinguishable from reference Pt films, independent of the initial deposit composition. Specifically, variations in composition 
caused by deposition parameters such as the beam current density the moisture content of the vacuum chamber used for EBID, and post-growth air exposure time do not affect the efficacy of the purification method. This is significant because, to date, the highest purity EBID-grown Pt deposits have been realized using $\mathrm{Pt}\left(\mathrm{PF}_{3}\right)_{4}$, which is water vapor sensitive and yields a deposit composition that varies with beam current density. ${ }^{22}$

\section{Conclusion}

We have demonstrated a method enabling localized, mask-free deposition of pure platinum that employs a combination of room temperature, direct-write electron beam induced deposition (EBID) using the inorganic precursor $\mathrm{Pt}\left(\mathrm{PF}_{3}\right)_{4}$, and low temperature $\left(\leq 400^{\circ} \mathrm{C}\right)$ post-growth annealing in $\mathrm{H}_{2} \mathrm{O}$. The annealing treatment removes phosphorous contaminants through a thermally-activated pathway involving fragmentation of $\mathrm{H}_{2} \mathrm{O}$ adsorbates to produce $\mathrm{O}$ and $\mathrm{H}$ species that react with $\mathrm{P}$ to form volatile phosphorous hydrides and oxides.
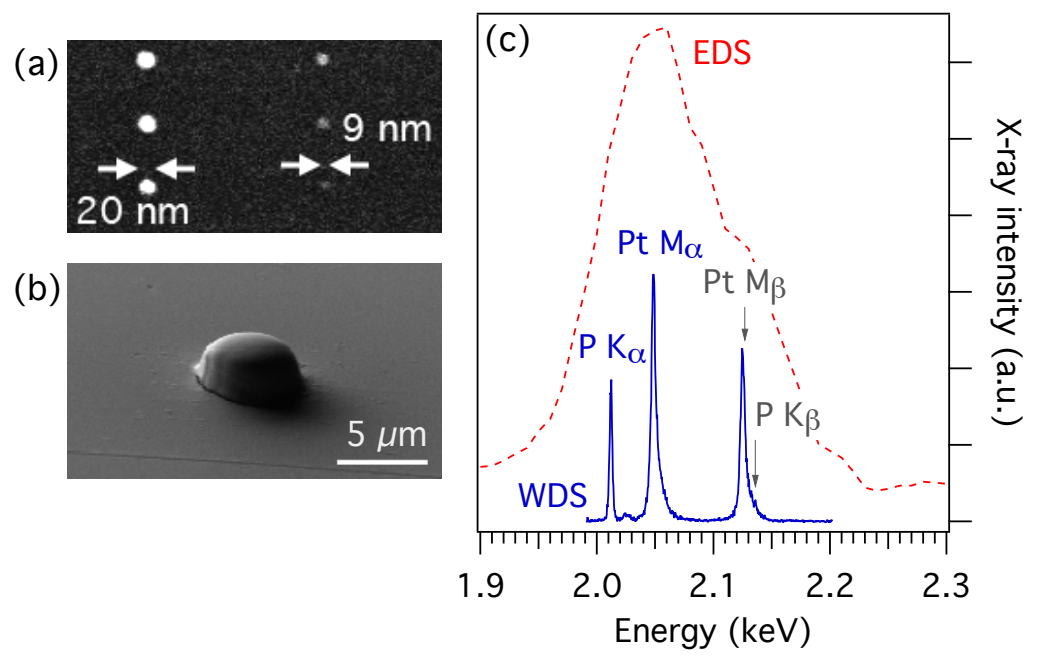

Figure 1: (color online) SEM images of a (a) nanodot array grown by $\mathrm{Pt}\left(\mathrm{PF}_{3}\right)_{4}$-mediated EBID using a Gaussian electron beam, and (b) deposit grown using a $5 \mu \mathrm{m}$, top-hat beam. (c) X-ray spectra showing the $\mathrm{Pt} \mathrm{K}_{\alpha}, \mathrm{Pt} \mathrm{M}_{\alpha}, \mathrm{Pt} \mathrm{M}_{\beta}, \mathrm{P} \mathrm{K}_{\alpha}$ and $\mathrm{K}_{\beta}$ X-ray lines. 


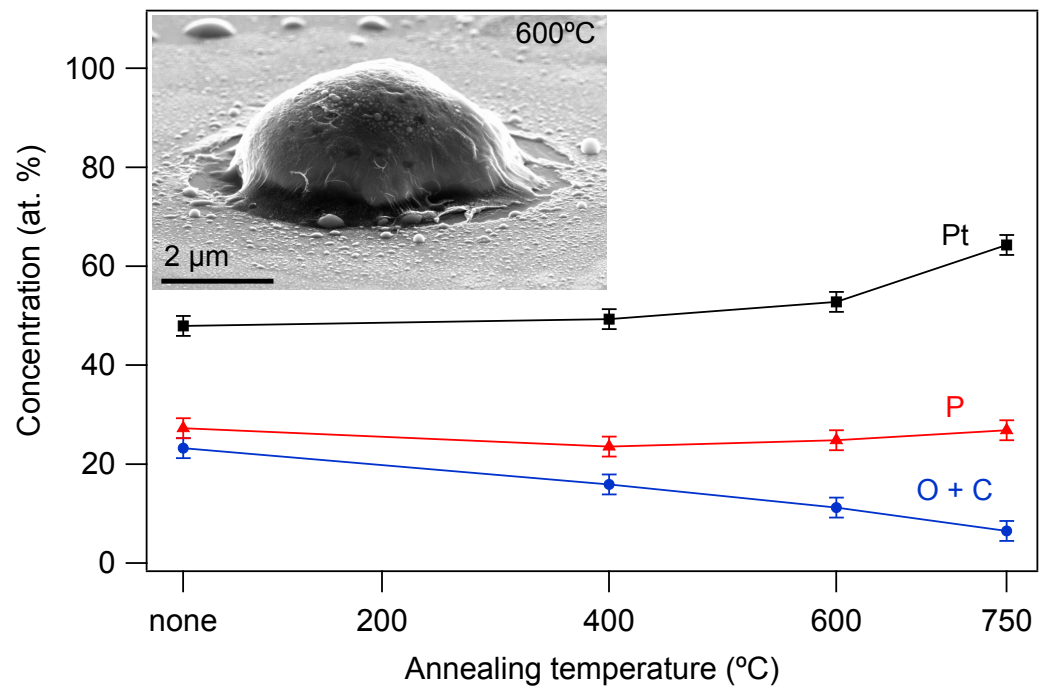

Figure 2: (color online) Deposit composition as a function of post-growth annealing temperature in vacuum (annealing time $=60 \mathrm{~min}$ ). Inset: $\mathrm{SEM}$ image of a deposit acquired after a $600^{\circ} \mathrm{C}$ annealing treatment.

\section{References}

(1) Utke, I.; Moshkalev, S.; Russell, P. Nanofabrication Using Focused Ion and Electron Beams; Principles and Applications; Oxford University Press, USA, 2012.

(2) van Dorp, W. F.; Van Someren, B.; Hagen, C. W.; Kruit, P. Nano Lett. 2005, 5, 1303-1307.

(3) Toth, M.; Lobo, C. J.; Knowles, W. R.; Phillips, M. R.; Postek, M. T.; Vladár, A. E. Nano Lett. 2007, 7, 525-30.

(4) Rykaczewski, K.; Hildreth, O. J.; Kulkarni, D.; Henry, M. R.; Kim, S.-K.; Wong, C. P.; Tsukruk, V. V.; Fedorov, A. G. ACS applied materials \& interfaces 2010, 2, 969-73.

(5) Fernández-Pacheco, A.; Serrano-Ramón, L.; Michalik, J. M.; Ibarra, M. R.; De Teresa, J. M.; O’Brien, L.; Petit, D.; Lee, J.; Cowburn, R. P. Scientific Reports 2013, 3, 1-5.

(6) Utke, I.; Hoffmann, P.; Berger, R.; Scandella, L. Applied Physics Letters 2002, 80, 47924794. 


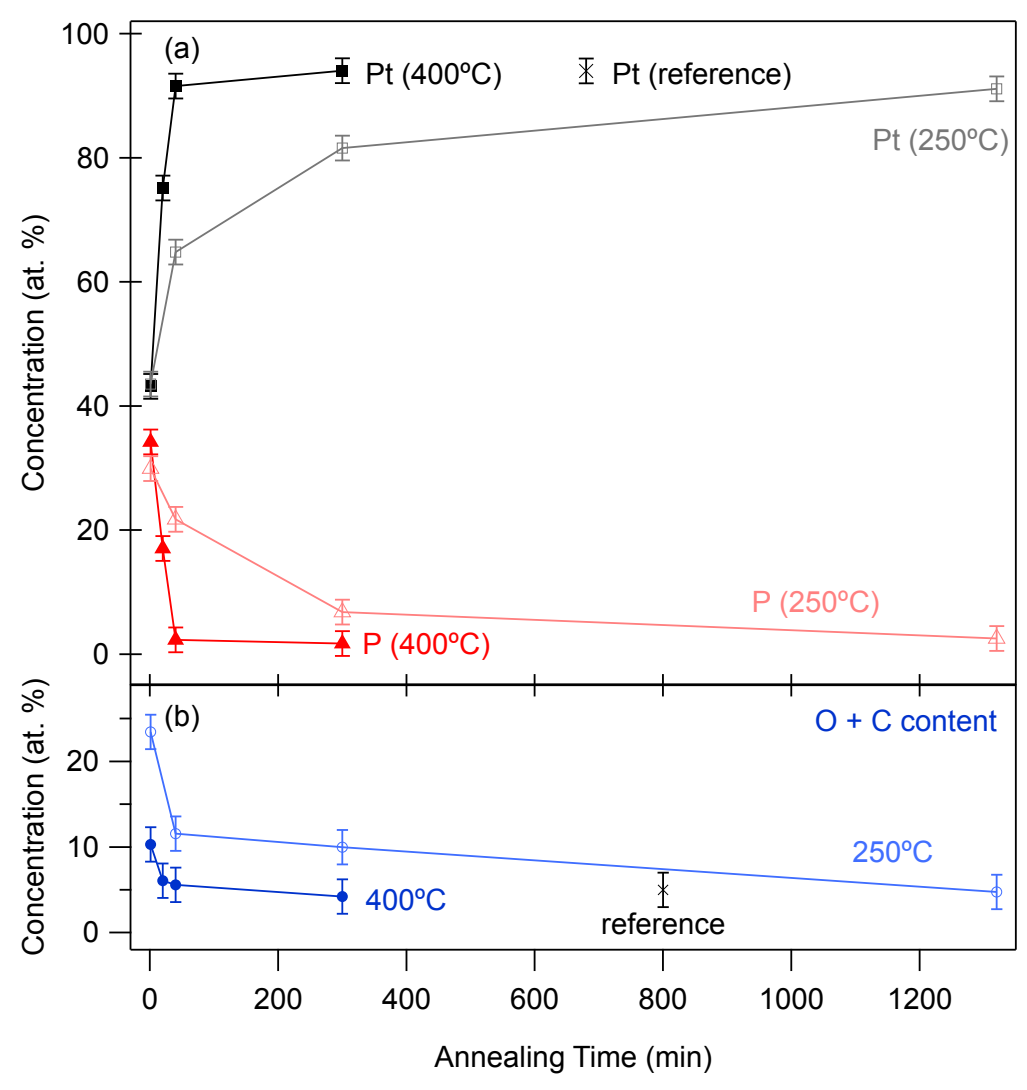

Figure 3: (color online) Composition of $\mathrm{Pt}\left(\mathrm{PF}_{3}\right)_{4}$-EBID deposits plotted as a function of annealing time in $\mathrm{H}_{2} \mathrm{O}$ vapor at 250 and $400^{\circ} \mathrm{C}$. Also shown is the measured composition of a reference, high purity Pt film.

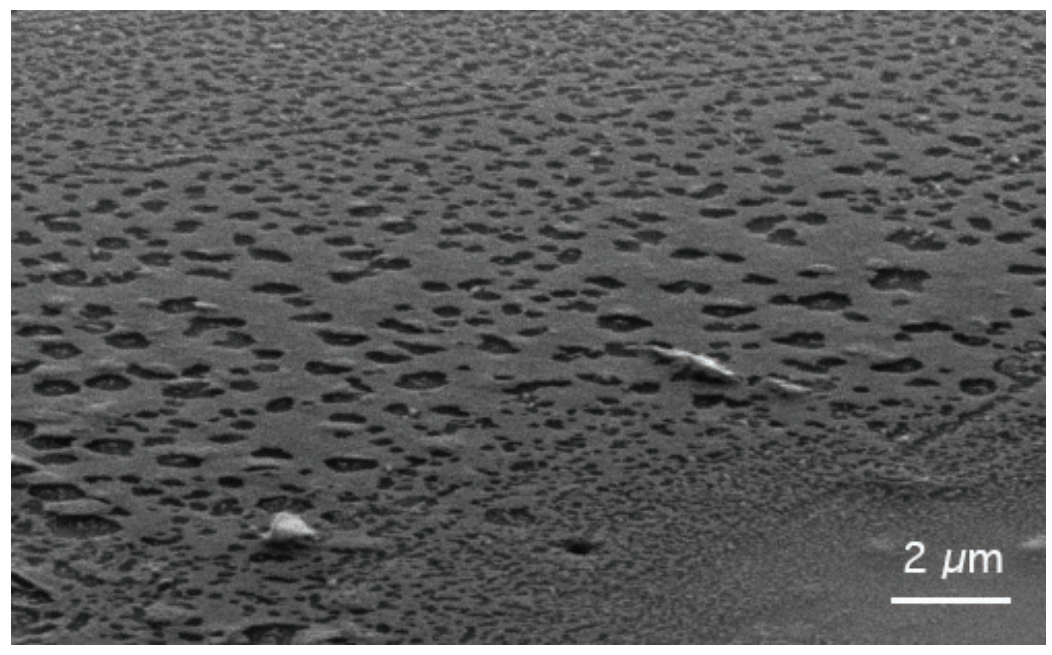

Figure 4: Etch pits in the substrate surface near deposits subjected to a $600^{\circ} \mathrm{C}$ anneal in $\mathrm{H}_{2} \mathrm{O}$.

(7) Gopal, V.; Radmilovic, V. R.; Daraio, C.; Jin, S.; Yang, P. D.; Stach, E. A. Nano Lett. 2004, 4, 2059-2063. 
(8) Hoeflich, K.; Yang, R. B.; Berger, A.; Leuchs, G.; Christiansen, S. Advanced Materials 2011, 23, 2657-2661.

(9) Jenke, M. G.; Lerose, D.; Niederberger, C.; Michler, J.; Christiansen, S.; Utke, I. Nano Lett. 2011, $11,4213-4217$.

(10) Botman, A.; Mulders, J. J. L.; Hagen, C. W. Nanotechnology 2009, 20, 372001.

(11) Rotkina, L.; Lin, J.-F.; Bird, J. P. Applied Physics Letters 2003, 83, 4426.

(12) Rotkina, L.; Oh, S.; Eckstein, J. N.; Rotkin, S. V. Physical Review B 2005, 72, 233407.

(13) Porrati, F.; Sachser, R.; Schwalb, C. H.; Frangakis, A. S.; Huth, M. Journal of Applied Physics 2011, 109.

(14) Porrati, F.; Kämpken, B.; Terfort, A.; Huth, M. Journal of Applied Physics 2013, 113, 053707.

(15) Utke, I.; Michler, J.; Gasser, P.; Santschi, C.; Laub, D.; Cantoni, M.; Buffat, P. A.; Jiao, C.; Hoffmann, P. Advanced Engineering Materials 2005, 7, 323-331.

(16) Bernau, L.; Gabureac, M.; Erni, R.; Utke, I. Angewandte Chemie-international Edition 2010, $49,8880-8884$.

(17) Li, J.; Toth, M.; Tileli, V.; Dunn, K. A.; Lobo, C. J.; Thiel, B. L. Applied Physics Letters 2008, 93, 023130.

(18) Li, J. T.; Toth, M.; Dunn, K. A.; Thiel, B. L. Journal of Applied Physics 2010, 107, 103540.

(19) Sachser, R.; Porrati, F.; Schwalb, C.; Huth, M. Phys. Rev. Lett. 2011, 107, 206803.

(20) Utke, I.; Hoffmann, P.; Dwir, B.; Leifer, K.; Kapon, E.; Doppelt, P. Journal Of Vacuum Science \& Technology B 2000, 18, 3168-3171.

(21) Wang, S.; Sun, Y.-M.; Wang, Q.; White, J. M. Journal of Vacuum Science \& Technology B: Microelectronics and Nanometer Structures 2004, 22, 1803. 
(22) Barry, J. D.; Ervin, M.; Molstad, J.; Wickenden, A.; Brintlinger, T.; Hoffman, P.; Meingailis, J. Journal of Vacuum Science \& Technology B: Microelectronics and Nanometer Structures 2006, 24, 3165.

(23) Botman, A.; Hesselberth, M.; Mulders, J. J. L. Journal Of Vacuum Science \& Technology B 2008, 26, 2464-2467.

(24) Botman, A.; Hagen, C. W.; Li, J.; Thiel, B. L.; Dunn, K. a.; Mulders, J. J. L.; Randolph, S.; Toth, M. Journal of Vacuum Science \& Technology B: Microelectronics and Nanometer Structures 2009, 27, 2759.

(25) Landheer, K.; Rosenberg, S. G.; Bernau, L.; Swiderek, P.; Utke, I.; Hagen, C. W.; Fairbrother, D. H. Journal of Physical Chemistry C 2011, 115, 17452-17463.

(26) Rosenberg, S. G.; Landheer, K.; Hagen, C. W.; Fairbrother, D. H. Journal of Vacuum Science \& Technology B: Microelectronics and Nanometer Structures 2012, 30, 051805.

(27) Mulders, J. J. L.; Belova, L. M.; Riazanova, A. Nanotechnology 2011, 22, 055302.

(28) Bishop, J.; Lobo, C.; Martin, A.; Ford, M.; Phillips, M.; Toth, M. Physical Review Letters 2012, 109, 1-5.

(29) Molhave, K.; Madsen, D. N.; Rasmussen, A. M.; Carlsson, A.; Appel, C. C.; Brorson, M.; Jacobsen, C. J. H.; Boggild, P. Nano Lett. 2003, 3, 1499-1503.

(30) Folch, A.; Tejada, J.; Peters, C. H.; Wrighton, M. S. Applied Physics Letters 1995, 66, 2080_ 2082.

(31) Perentes, A.; Hoffmann, P. Chemical Vapor Deposition 2007, 13, 176-184.

(32) Lukasczyk, T.; Schirmer, M.; Steinruck, H. P.; Marbach, H. Small 2008, 4, 841-846.

(33) Lukasczyk, T.; Schirmer, M.; Steinruck, H. P.; Marbach, H. Langmuir 2009, 25, 1193011939. 
(34) Ervin, M. H.; Chang, D.; Nichols, B.; Wickenden, A.; Barry, J.; Melngailis, J. Journal of Vacuum Science \& Technology B: Microelectronics and Nanometer Structures 2007, 25, 2250.

(35) Riazanova, A. V.; Rikers, Y. G. M.; Mulders, J. J. L.; Belova, L. M. Langmuir 2012, 28, 6185-6191.

(36) Mackus, A. J. M.; Mulders, J. J. L.; van de Sanden, M. C. M.; Kessels, W. M. M. Journal Of Applied Physics 2010, 107, 3.

(37) Randolph, S.; Botman, A.; Toth, M. Particle 2013, Early view: http://onlinelibrary.wiley.com/doi/10.1002/ppsc.201300036/abstract.

(38) Lobo, C. J.; Martin, A.; Phillips, M. R.; Toth, M. Nanotechnology 2012, 23, 375302.

(39) Hovington, P.; Drouin, D.; Gauvin, R. Scanning 1997, 19, 1-14.

(40) Friedman, J. F.; Miller, T. M.; Friedman-Schaffer, J. K.; Viggiano, A. A.; Rekha, G. K.; Stevens, A. E. Journal Of Chemical Physics 2008, 128, 104303.

(41) Hern, J. In Introduction to analytical electron microscopy; Hern, J., Goldstein, G. I., Joy, D. C., Eds.; Plenum Press: New York, p 481.

(42) van Gelder, W.; Hauser, V. E. Journal of The Electrochemical Society 1967, 114, 869. 


\section{Graphical TOC Entry}

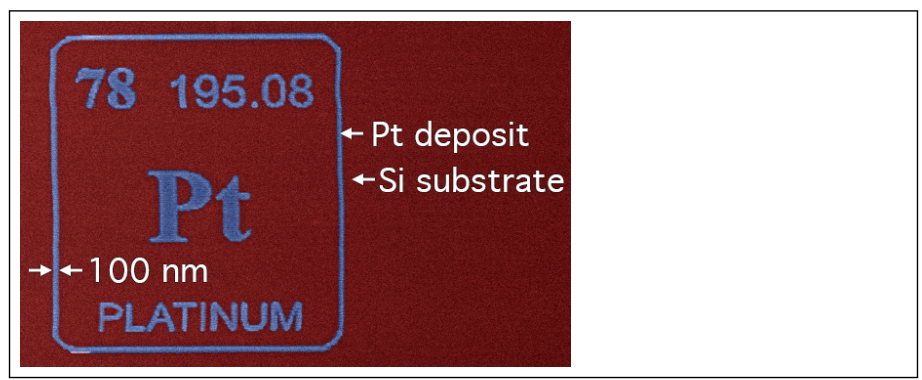

